\title{
Food and Beverage Innovative Product Development Model
}

\author{
Smita Mortero $^{1}$, Prof. Dr. Jirarat Anantagool ${ }^{2}$, Prof. Emeritus ${ }^{3}$ Dr. Achara Chandrachai ${ }^{4}$ \\ ${ }^{1}$ Technopreneurship and Innovation Management, Graduate School, Chulalongkorn University, Thailand \\ ${ }^{2}$ Department of Food Technology, Faculty of Science, Chulalongkorn University, Thailand \\ ${ }^{3,4}$ Chulalongkorn Business School, Chulalongkorn University, Thailand
}

\begin{abstract}
The research aimed to develop the process of the innovative products that can be applied to food and beverage products with a systematic review of the literature, considering various ideas and theories. The study found that they are discussed in a wide gap. Next, the study aimed to explore the acceptance of the food and beverage innovative product development model. Nowadays, the product life cycle cannot go on as the market changes, so there are limitations, led to create the model which is divided into 3 Phases, Phase 1 Product Design Development, Phase 2 Prototype and Phase 3 Industry Scale and Commercialization. Then, the research results explore that the acceptance of the model using the focus group method. It is known that many entrepreneurs of Small and Medium Enterprise (SME) did not develop a systematic product, made it failed in a situation with a lot of competitors in the market and difficulty adapting and solving problems. When entrepreneurs have studied step by step of the food and beverage innovative product development model, it makes easier to understand and have more direction for product development to bring about new products or processes in lower costs and increased income. There is a proper use of time and save resources, including raw materials, personnel, as well as reducing environmental destruction and using full efficiency resources. This model is role as a circle can be made more products line from the same resources which is back to create from the detail of the product design and also, can be start a new thing on the concept development.
\end{abstract}

Keywords: Food and Beverage Innovation; RDI; Entrepreneur; SME; Innovative Product Development Model 


\section{Introduction}

Food and drinking water are important factors that the body needs. Food is intertwined with local cultures and wisdom of each country of the world which reflects the food that tells the uniqueness of different countries. Especially in Thailand, food in each region differs, according to geography, climate and culture. In addition, drinking water help thirsty and likewise brings fruits and vegetables to develop into a variety of beverages along with food to expresses the traditional culture, living and also uses raw materials such as local spices and herbs created food and drink. It is forwarding and communicating its uniqueness to different places to lead the food and beverage industry highly competitive.

Therefore, the food and beverage products development play an important role in driving resource enabling economies both produced for sale in the country and exported as in the present. Despite the crisis from epidemic natural disasters including the war, food and beverages remain one of the top priorities for food and beverage quarantine in times of crisis such as Covid-19. No one has predicted how long it will happen and last. Even if one event passes, an unexpected event can happen again. One of the things that makes it necessary to realize is prepared for every situation. In particularly, food and beverages are essential to the human body of all ages and states.

Food and beverage innovative product development will distinguish foods in their taste, features, appearance, quality and optimal shelf life which must comprise many knowledge areas as creative development, process and technology that can be commercially produced. If the entrepreneur intends to produce the product without study the unmet needs of consumer or make the same things in the market which is made an imbalance of demand and supply. Entrepreneurs with a high investment can stay in the market longer than a smaller one in a competitive market. Many small entrepreneurs use the funds that come from saving or loan the money to invest which may not be able to go through each phase of the product lifecycle. Thus, they had to close the business. Now, the food and beverage business have many competitors and the product cycle is shorter than before with more options in the rapidly changing trend.(Silinevica, Igavens, \& Amantova-Salmane, 2016) Researcher therefore realized that the study and development of innovative food and beverage products are very necessary and important nowadays. It also helps the product to be accepted by consumers and can be commercially available and compete in the market with efficiency and sustainability.

\section{Objectives}

1. To study the innovative product development processes for food and beverage

2. To explore the acceptance of the food and beverage innovative product development model 


\section{Literature Review}

The objectives aimed to study the process of developing innovative products that can be applied to food and beverage products by the literature review with the study of product development theories and models. The main problem for SME and Thai community enterprises today is still the issue of developing and extending products to be able to grow steadily. Most products are still lacking in development and design to meet market needs. Especially, the products have not been varieties, lack of uniqueness, outstandingness and differentiation both in terms of appearance and functionality. Most of the entrepreneurs still have production regardless of market demand. There are imitations of products without creativity. Making it impossible to add value to those products because the product cannot be sold at a high price. Despite the fact that consumers in the market, especially abroad, have confidence in the quality and standard of products from Thailand.(smethailandclub, 2016)

Therefore, the new product development process is important to help entrepreneurs develop innovative products at the community level to be a standard product and meet the needs of the market and the good new products must be effective to meet the needs of the target audience in short time to reduce costs. Product development has grown and more important as a necessity to stay competitive, especially with global competition. The product must be profitable throughout its life cycle before it can be decided to allow it to be marketed.(Kocakulah \& Austill, 2006) The new product development must be realised the product life cycle of the product to forecast, it is worth to invest in new product development.

\subsection{Product Life Cycle}

The product life cycle is an important nowadays which is not long more than year as before anymore if the products have not value added. It divided into development phases, introduction, growth, maturation, and product decline. The timing of these phases is variable, the timing of a product largely depends on the product demand own the market, the production costs and revenue generated by the product. If the product is still in demand and the production costs are gradually decreasing, led to longer product life. On the other hand, if the production costs are too high and the demand is limited so the product will be gone soon. Understanding the product life cycle can help business owners plan marketing mixes to fully manage each step. The goals of product lifecycle management are value addition and the maximum profit at each step.(UKEssays, 2018) The development of new products will be complete that relevant theories and models have emerged. There are interesting and valuable to product development.

\subsection{Product Develop}

Product development to creative innovation nowadays. There are academics who are interested in processes that bring about new products or processes which may result in lower costs, increased income. There is a proper use of time, save resources for the objects, the personnel, and the environment. Depending on the company, different types can be used or can be applied accordingly, which depends on the management of each part for example, it is divided into the front part of innovation and the later part of innovation or some concepts are divided into the front of innovation development and bring it to the commercial market. 
In other words, it can be utilized to benefit society with academics giving a detailed studied on the innovation front part that (Dziallas, 2020) Companies face the challenge of choosing the right idea early in the early or front end innovation process due to limited resource and budget constraints. The pursuit of ideas are presented on all issues in the early stages of the innovation process, including the generation of ideas, concept definition, perception, opportunity and evaluation; Where there are many promising new ideas for innovation that have not become a product. This could be companies often lack the knowledge of appropriate assessment methods to identify the most relevant topics from the number of good ideas. Then, there are combined with the uncertainty that characterizes the crystallization of the front end, this lack of knowledge means that the company may not provide sufficient importance for a structured assessment process and evaluation method including indicators for new product development.

A solution of this problem is proposed by helping companies align their choice of ideas with their goals and resources. The use of indicators leads to transparent innovation decisions more traceability and reliability. This reduces the complexity at the back of the innovation process by making the right decisions early, companies can mitigate the risk of major failures. It also helps with the costs changing in the later stages of development.

Academic (Thanasopon, Papadopoulos, \& Vidgen, 2016) suggest that the creation of commercial will be successful ideas by the company should have received and gather information including knowledge from external sources and cooperation with customers and other organizations such as suppliers, competitors, universities, etc. in the early stages of the innovation process. This is in line with the concept of "inbound open innovation" proposed by Chesbrough that the companies can and should use external concepts including internal concepts to gain a competitive advantage through innovation. That openness is the result of innovative achievements. Innovative companies can reduce research and development costs, increase productivity, innovation and originality and reduce time to market.

Figure 1: Figure shows the Stage Gate Process of Stage Gate Process Model

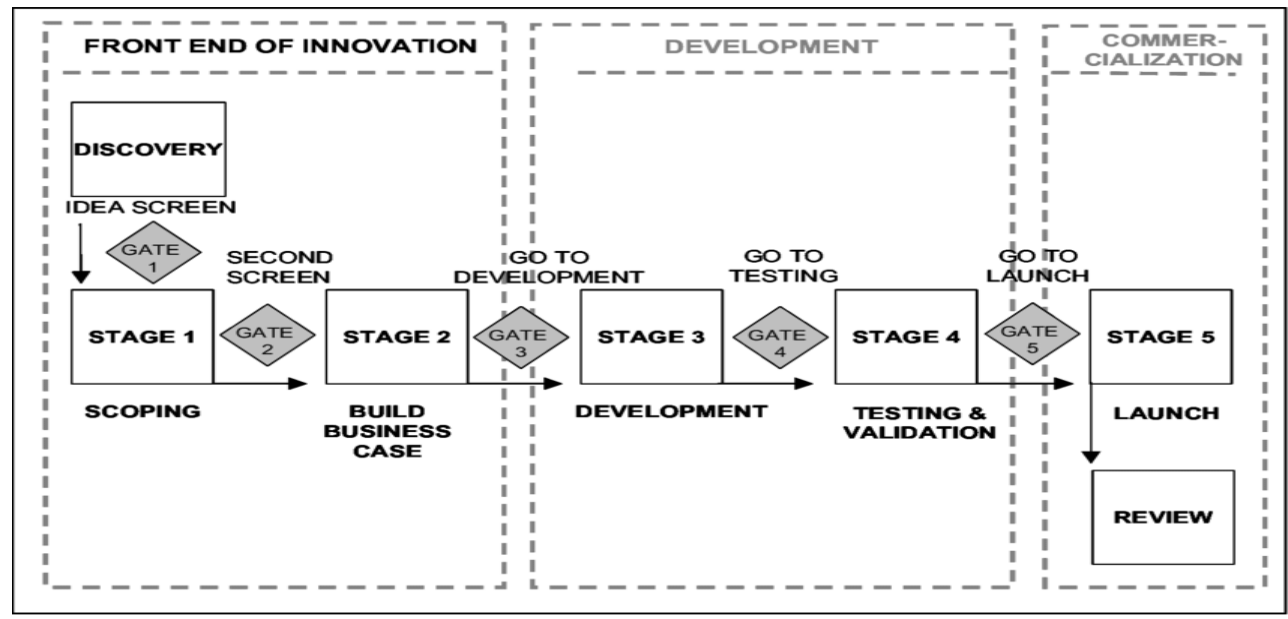

Cooper's Stage-gate Process as an Example for Innovation Process Models (Cooper, 2008) 


\subsubsection{Stage Gate Model by Robert G. Cooper}

Stage-Gate Model(Cooper, 2008) It is a method that can be used to make the product development process more efficient. It is a blueprint for managing new product processes from idea to product launch. The pre-defined process at each stage consists of a series of activities to achieve the desired results before continuing to the next stage of product development. The way through each step is called a door, each door has a process that controls the quality. It checks each point according to the goals set before going to the later door. The origin of the Stage-Gate Model Cooper takes experience, suggestions and observations from managers and companies in over 60 self-study case studies. Stage-Gate Model Originally, the early design had a total of 5 gate processes or steps.

There are 5 processes in the Discovery process before starting at that first stage was added to later models to find opportunities and generate new ideas. Step 1 Scoping : A quick initial audit of each project by seeking information from research to help reduce the number of projects. Step 2 Build the Business Case : A more technical, thorough investigation with core marketing and research. The business case must include product definitions, product reasonability and project plan. Step 3 Development: The detailed new product design and development with simple product testing. In addition, production plans and market launch plans are being developed. Step 4 Testing and Validation : Extensively test products in both laboratory and factory markets. Step 5 Launch : The beginning of production to marketing and sales to the full pattern with the launch of the market, production, operations, distribution and quality assurance. Lastly, the review after the launch makes the operation of the commercial product more efficient. Each step, before going through to the next door, needs to be delved into the sub-activities thoroughly for the operation for innovation teams.

\section{Strength of Stage Gate Model}

1) Well-structured innovation can provide a competitive advantage 2) Accelerating product development is essential as product life is shortened 3) There is an increased chance of success of new products and prevent bad projects before wasting time to produce and help to change the direction with a greater chance of success 4) It is a model for dividing complex innovation processes in large organizations into smaller steps 5) See the big picture, allowing prioritization and focus on goals 6) Integrated marketing approach 7) There is joint input and participation of employees from different departments in the organization, do not separate $\mathrm{R} \& \mathrm{D}$ and marketing but look at the overview together from the beginning, search for new product making 8) Able to combine performance indicators such as Net Present Value, the difference of the Present Value of the total net cash outflows and net cash inflows using Net Present Value (NPV) to analyze the feasibility of the project

\section{Limitations of the Stage Gate Model}

1) Although within the activities of each phase can be performed in parallel by the way of the doors are sequential. Some innovation experts believe that product development should be organized not parallel, but loops instead 2) The original Stage-Gate framework did not manipulate the Discovery process to generate new ideas 3) It is difficult to find new solutions between organization and creativity, both of which are very important to innovation 


\section{$4^{\text {th }}$ International Conference on BUSINESS, MANAGEMENT \& ECONOMICS}

Figure 2: Figure of Design Thinking

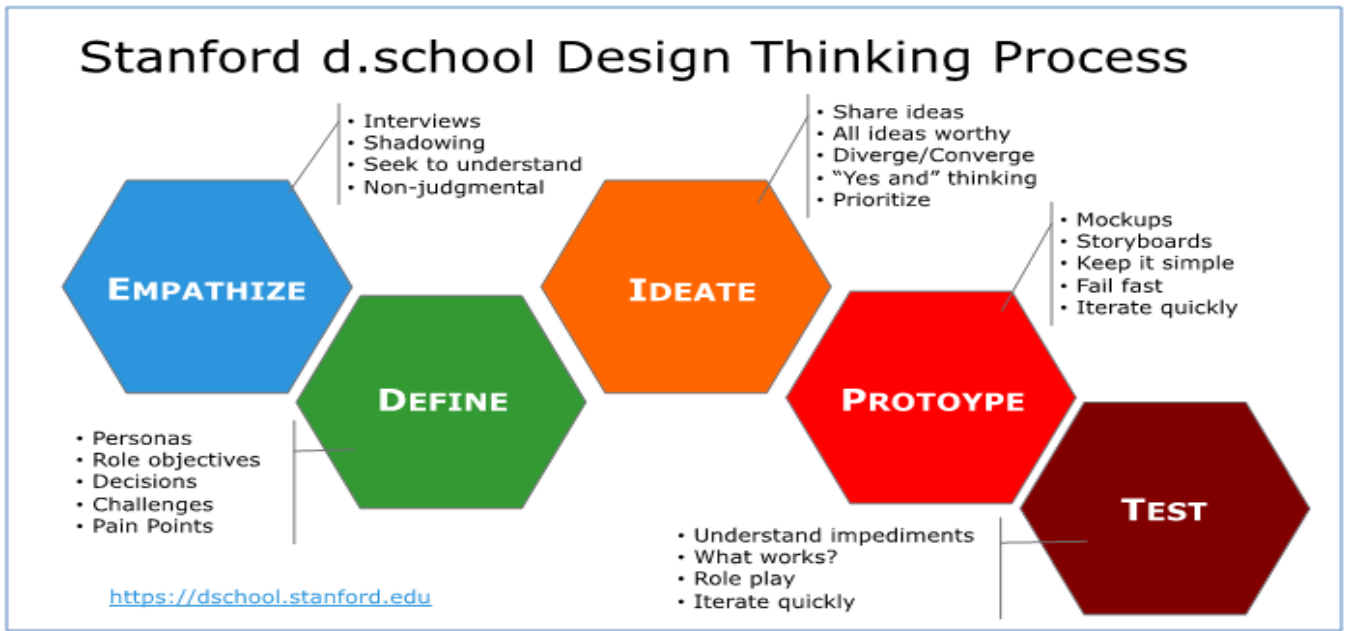

d. School Design Thinking(Terrar, 2018)

\subsection{2 d. School Design Thinking(Terrar, 2018) focuses on five main things:}

Step 1 Empathy : Understanding the target audience as much as possible drill down to see the real problem. Step 2 Define : Data analysis by asking the questions and drive new ideas. Step 3 Ideate : Massive brainstorming with a focus on finding ideas that will solve as many problems as possible by the most versatile. Step 4 Prototype : Create a test prototype and ask questions to see the errors as quickly as possible. Step 5 Test : Take the model that is tested to give the real target audience to experiment and bring feedback or various recommendations to further improve

Figure 3: Figure of Design Sprint

5 Phases of a Design Sprint

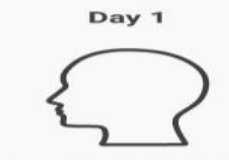

Understand
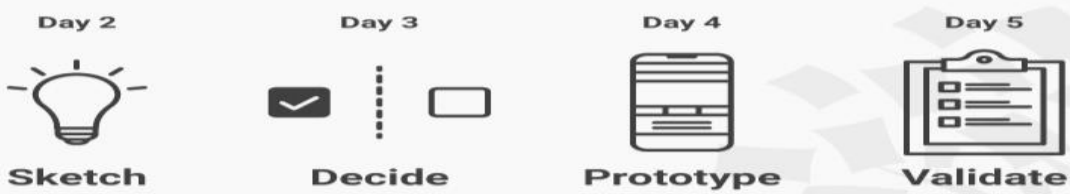

Design Sprint created by Google Ventures(InteractionDesignFoundation, 2010)

2.2.3 Design Sprint (Google Venture) : The sprint is a five-day process for answering critical business questions through design, prototyping, and testing ideas with customers. Working together in a sprint, you can shortcut the endless-debate cycle and compress months of time into a single week. Instead of waiting to launch a minimal product to understand if an idea is any good, you will get clear data from a realistic prototype. The sprint gives you a superpower: You can fast-forward into the future to see your finished product and customer reactions, before making any expensive commitments. Design Sprint(Knapp, 2016) This page is a DIY guide for running your own sprint. It has 5 important steps: Step 1 Understand your goals on Day 1, you will map out the problem and pick an important place to focus. Step 2 Sketch on Day 2, you will sketch competing solutions on paper. Step 3 Decide : choose and 
decide to complete the process on Day 3, you will make difficult decisions and turn your ideas into a testable hypothesis. Step 4 Prototype Storyboard Modeling on Day 4, you will hammer out a high-fidelity prototype. Step 5 Validate for users to actually test on Day 5, you will test it with real live humans.

\subsection{Innovation}

Innovation Driven Economy is very important in doing business today. It is a tool to help SME stay ahead of the competition. It can meet the needs of consumers effectively and also a way for businesses to survive in the increasingly intense market competition. Despite the trend of entrepreneurs in Thailand begin to pay more attention to development, innovation and research but when comparing this proportion with the number of SME in Thailand, less than 1 percent of them have used research and innovation to transform their businesses. Because research and innovation can not only make businesses survive or compete with competitors but it also paved the way for success as well as a large industry. It can be seen that growing companies tend to invest in research and innovation. It is also an important factor in determining consumer behavior and building brand loyalty.(SMEThailand, 2019)

Innovation, in addition to enhancing competitiveness and differentiation between competitors, is also a tool for growth business sustainability. While driving SME innovation often encounters various problems and obstacles that the existing businesses are not successful. Including, Thailand will soon step into the ASEAN Economic Community, will face competition business that is becoming more concentrated Therefore, it is essential that entrepreneurs should know and understand the limitations of driving innovation in SME adding guidelines and models for driving innovation of various countries as a guideline for planning and formulate strategic policies to be able to grow sustainably.

Therefore, SME to grow must focus on innovation development and research in 3 areas:

1. Developing innovative products and services that are new and unfamiliar. It must be new and unique with the same product or service. In order to impress consumers and has an edge over competitors such as after-sales service, modern product design (Products or services) that have a variety of functions, creating content or presenting content through various media that are attractive ex. manufacturing of health products, etc.

2. Focusing on innovation related to the manufacturing process. It will require various tools that are modern able to apply new technologies to enhance efficiency and productivity as well as reducing environmental impact, such as the introduction of automation in the production process and use of renewable energy innovation for cost reduction etc.

3. Research development and marketing innovation. This is a combination of using technology and creativity to create exponential business growth. There is no need for huge investments in order to attract consumers to use products and services such as having a storage system (Big Data), using social media. The presence of new communication systems are both directly and indirectly with consumers, etc.

Type of Innovation ; Incremental innovation is a small improvement made to the product or the existing methods of the company. The change focuses on improving the efficiency of developing existing products. Productivity and competitive differentiation, these low-cost enhancements help the company differentiate itself from the competition to add or reduce something to suit the trends including the packaging, colors and details on the original bundle, begin from design a new product. Breakthrough innovation is a development 
innovation or a cutting-edge innovation which comes from working together to come up with new ways to find future needs. Adjusting the perspective of an ever studied potential market, add new developments to make changes that are different from the original, such as product features, product properties or product texture, real solutions to customers effective further development of the findings. Thus, creating opportunities for new innovations, that can reach consumers deeply solve problems for consumers on the spot, begin from the concept development stage.

\section{METHODOLOGY}

Methodology of this research topic is food and beverage Innovative Product Development Model to find the answers by following the steps of the research objectives lead to the model for the development innovative products of food and beverages that the researcher aims to study divided into 2 parts ;

Part 1 To develop model of innovative product development processes for food and beverage with a systematic review of the literature.

Part 2 To explore the acceptance of the food and beverage innovative product development model using the focus group method.

This research is a qualitative research. The study consists of sub-details to find research findings by defining as a method of research or activities must be performed specify the target population of SME entrepreneurs in food and beverage business by selecting only sampling that is representative of the sample group of 50 people. The fogus group was divided into two groups of 25 people each preparing discussion questions to get the answers of the research. The research design has a clear goals and questions including prototype model. The methods are observed those who join the focus group, setup conversation pattern details and explain the model to explore the understanding. Then, a key man must observe behavior, listening, ask question and take a note. There is a person responsible for keeping the group discussing the specified issues, collected information and data analysis methods, in order to, get the desired results to explain further research results.

\section{ReSUlt AND Discussion}

Results from this research study divided the objective into 2 parts.

4.1 Part 1: Research information from various sources, the knowledge gained to process relevance to the development of innovative food and beverage products to develop new models for SME entrepreneurs who are interested in developing structured products and work processes such as criteria for validation and measurement have clear goals.

The results of the study brought various valuable knowledge with good patterns to develop to meet the context of the development of innovative food and beverage products. Since Thailand has more than 3 million SME entrepreneurs, less than $1 \%$ of them are interested in the innovation for product development.(SMEThailand, 2019) That means in the market there are similar products made a lot of options and high market share, low profit, despite the fact, that Thailand is a very high quality food source. It is rich in vegetables and herbs, so developing a model to help increase the potential of SME is very important.

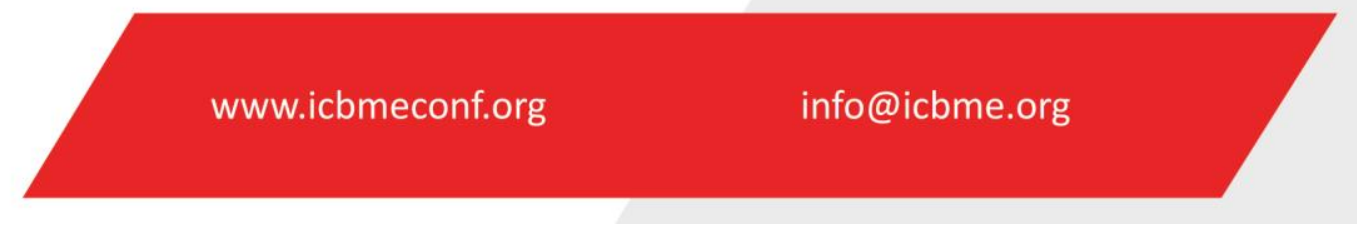




\section{$4^{\text {th }}$ International Conference on BUSINESS, MANAGEMENT \& ECONOMICS}

The study also found that the product life cycle is shorter, if the investment has made mistakes, SME entrepreneurs will have difficulty solving problems in various fields. They must try to empty product both warehouse and store and to find new products including moving to new markets, need to invest money for advertising and public relations. Therefore, linear product development will have a big impact in an era of shorter product life cycles.

When taking all the advantages of various knowledge to develop new models to help Thai SME overcome the obstacles of the red ocean, it can be summarized as follow

Table 1: Table comparing the stages of NPD Process and F\&B Innovation Development Model

\begin{tabular}{|c|c|c|c|}
\hline $\begin{array}{l}\text { Stage-gate } \\
\text { (Robert G. Cooper) }\end{array}$ & $\begin{array}{l}\text { Design Thinking } \\
\text { (D. School) }\end{array}$ & $\begin{array}{l}\text { Design Sprint } \\
\text { (Google Venture) }\end{array}$ & $\begin{array}{c}\text { Food and Beverage } \\
\text { Innovation Model }\end{array}$ \\
\hline 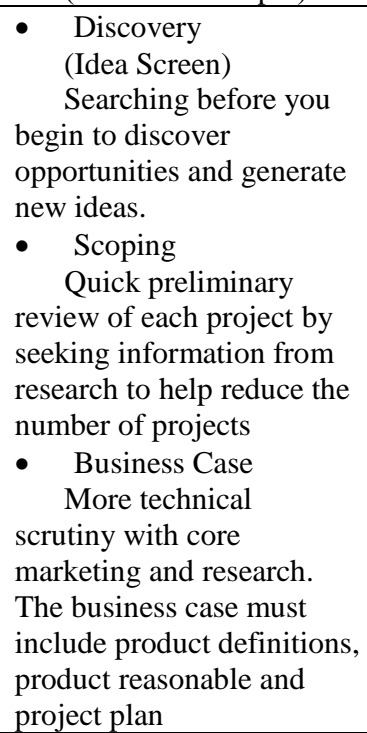 & $\begin{array}{l}\text { Empathy } \\
\text { Understanding the target } \\
\text { audience as much as } \\
\text { possible, delve into the real } \\
\text { problem } \\
\text { - Define } \\
\text { Data analysis, ask the } \\
\text { questions and drive } \\
\text { creativity without thinking. } \\
\text { - Ideate } \\
\text { Massive brainstorming } \\
\text { with a focus on finding ideas } \\
\text { that will solve as many } \\
\text { problems as possible as the } \\
\text { most versatile }\end{array}$ & $\begin{array}{l}\text { - Understand } \\
\text { map out the problem and } \\
\text { pick an important place to } \\
\text { focus } \\
\text { - Sketch } \\
\text { competing solutions on } \\
\text { paper } \\
\text { Decide } \\
\text { make difficult decisions } \\
\text { and turn your ideas into a } \\
\text { testable hypothesis }\end{array}$ & $\begin{array}{l}\text { Phase } 1 \\
\text { - Product Design } \\
\text { Development } \\
\text { »Discovery } \\
\text { »Market Potential } \\
\text { »Concept } \\
\text { Development } \\
\text { »Concept Testing } \\
\text { »Product Design } \\
\text { ○ Criteria for Product } \\
\quad \text { Selection } \\
\circ \text { Differentiation } \\
\circ \text { Benchmark Formula } \\
\circ \text { Food Raw }\end{array}$ \\
\hline $\begin{array}{l}\text { Development } \\
\text { Thorough new product } \\
\text { design and development } \\
\text { with simple product } \\
\text { testing. In addition, } \\
\text { production plans and } \\
\text { market release plans are } \\
\text { being developed. } \\
\text { - Testing } \\
\quad \text { Extensive product } \\
\text { testing in both laboratory } \\
\text { and factory markets }\end{array}$ & $\begin{array}{l}\text { Prototype } \\
\text { Create a test prototype } \\
\text { and ask questions to spot the } \\
\text { mistakes as quickly as } \\
\text { possible. } \\
\text { - Test } \\
\text { Take the model that is } \\
\text { tested to give the real target } \\
\text { audience to experiment and } \\
\text { bring feedback or various } \\
\text { recommendations to further } \\
\text { improve }\end{array}$ & $\begin{array}{l}\text { - Prototype } \\
\text { make difficult decisions } \\
\text { and turn your ideas into a } \\
\text { testable hypothesis to make } \\
\text { a model } \\
\text { - Validate } \\
\text { test it with real live } \\
\text { humans }\end{array}$ & $\begin{array}{l}\text { Phase } 2 \\
\text { - Prototype } \\
\text { »PD } \\
\text { »Sensory Test } \\
\text { »Market Testing }\end{array}$ \\
\hline $\begin{array}{l}\text { - Launch } \\
\text { Full start of production } \\
\text { to marketing and sales with } \\
\text { the launch of the market, } \\
\text { production, operations, } \\
\text { distribution and quality } \\
\text { assurance }\end{array}$ & & & $\begin{array}{l}\text { Phase } 3 \\
\text { - Industry Scale and } \\
\text { Commercialization } \\
\text { » Upscale } \\
\text { » Launch }\end{array}$ \\
\hline $\begin{array}{l}\text { Post-Launch Review } \\
\text { Post-launch reviews } \\
\text { for more efficient } \\
\text { operation of commercial } \\
\text { products }\end{array}$ & & & $\begin{array}{ll}\text { Post Launch } \\
\text { - Incremental » Product } \\
\text { Design } \\
\text { - } \begin{array}{l}\text { Breakthrough » Concept } \\
\text { Development }\end{array} \\
\end{array}$ \\
\hline
\end{tabular}

All the theories can be used to develop new products with Food and Beverage Innovative Development Process (F\&B IDP) as shown in Figure 4, which suit to food and beverage 


\section{$4^{\text {th }}$ International Conference on BUSINESS, MANAGEMENT \& ECONOMICS}

product development. Especially, the model must be put the innovation to the process. It is not normal as simple product development, but it must be specific for the innovation of food and beverage product development. It can be shown on the front end of innovation process in figure 4.

The extraordinary on the product designs are Criteria for product selection, Differentiation, Benchmark formula and Food raw which are difference from the other products by the details. After the Post Launch, it is important to determine how well a product meets the market for consumers. The strategic adjustments to support a shorter product life cycle with incremental innovation product development will help deliver faster products to market and get quick feedback. While implementing a breakthrough development strategy will take time to deepen the synthesis of information without forgetting to improve the efficiency of personnel because when entrepreneurs have sufficient understanding of the needs of the target market, a revolutionary innovation can be achieved. For example, using technology to assist in various processes, Iot system (Internet of Things System) to help use Platform or Application to be convenient, fast, modern, and may also be able to store customer data that is big data to increase the capacity to go on developing innovative products in the future as well.

Figure 4: Figure of Food and Beverage Innovative Development Process (F\&B IDP)

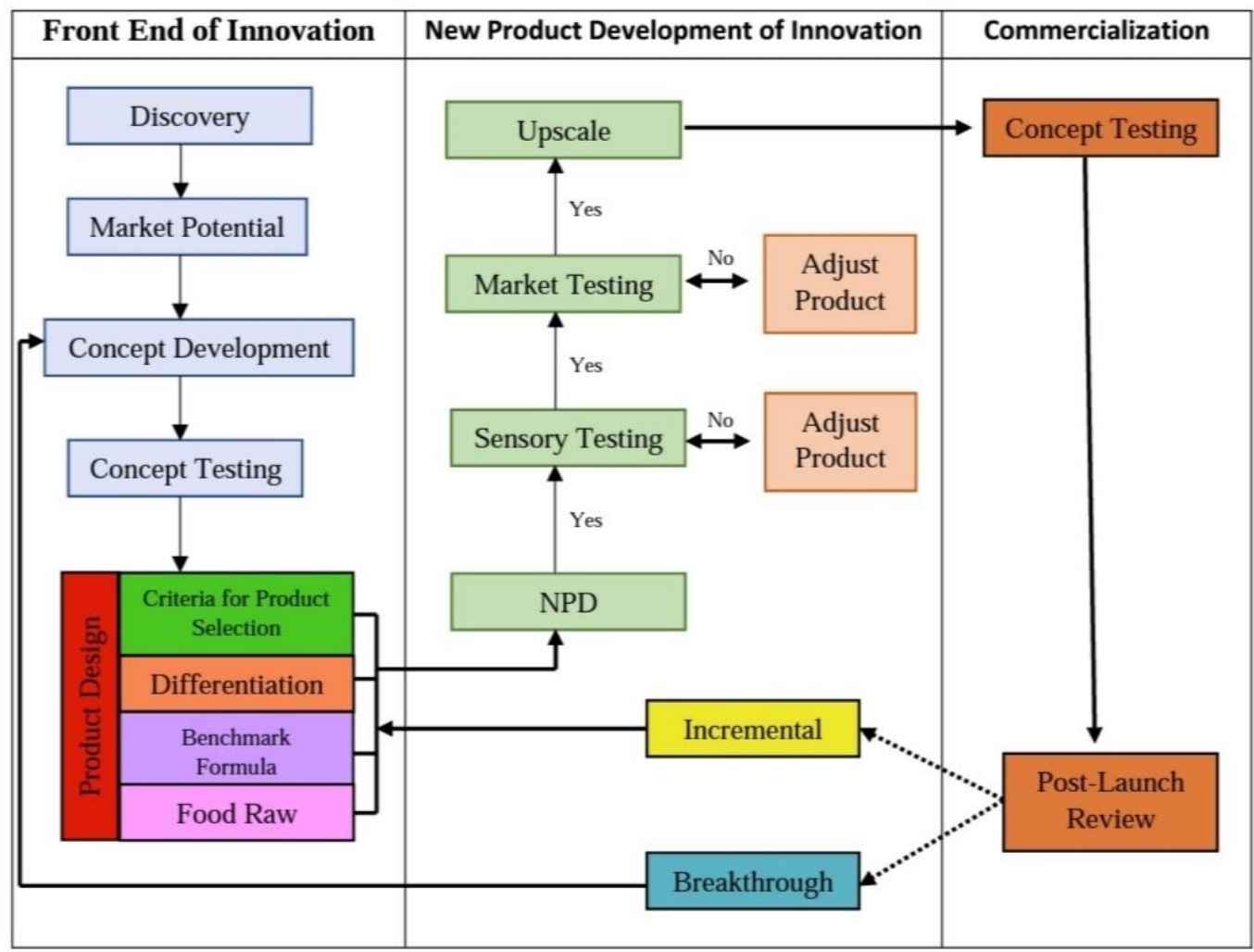

Food and Beverage Innovative Development Process ( $F \& B I D P)$

From Figure 4, Food and Beverage Innovative Development Process (F\&B IDP) can be easily explained in Figure 5, Food and Beverage Innovation Model, divided into 3 main phases 


\section{$4^{\text {th }}$ International Conference on BUSINESS, MANAGEMENT \& ECONOMICS}

Figure 5: Figure of The food and beverage innovative product development model

Discovery

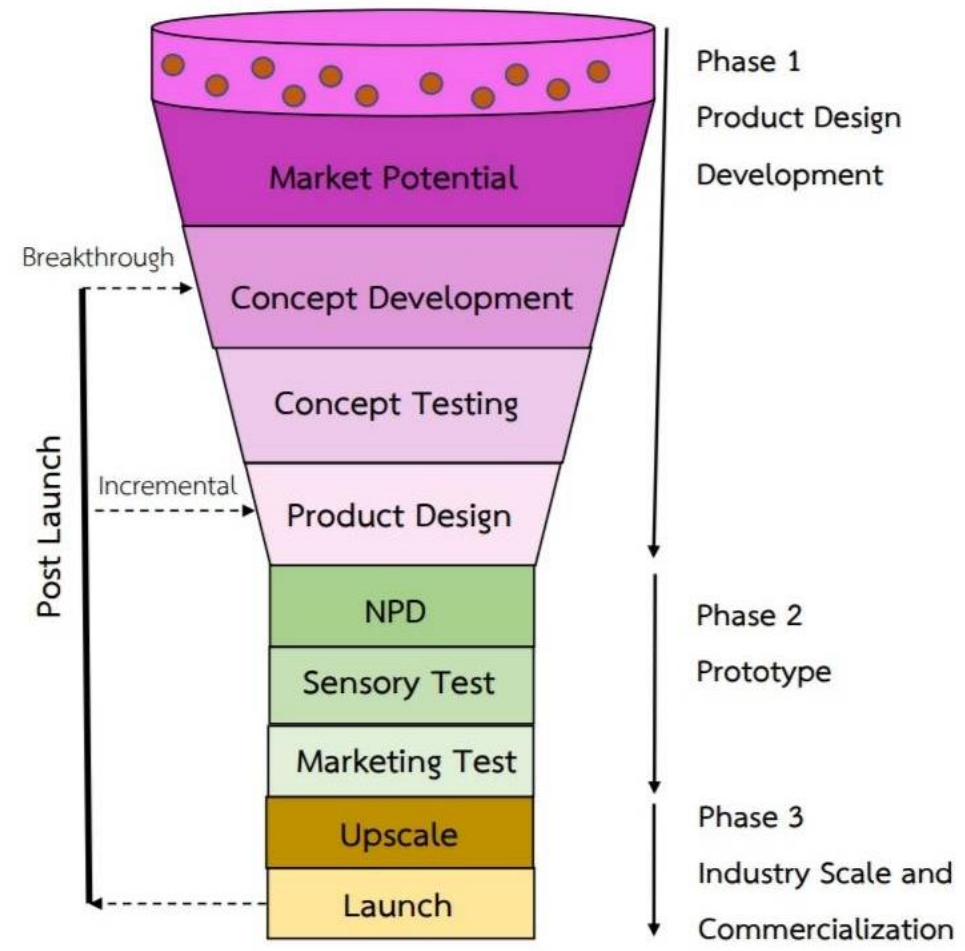

The food and beverage innovative product development model

Phase 1 Product Design Development

This section starts with review literature to find spaces that can produce food and beverage products. The possibility of the target audience study the food and beverage products available in the domestic and international markets, it can be concluded that the products available in the market today and study current technologies in the food industry. Select technology that can be used to produce product innovation and process innovation for food and beverage by studying future trends in food and beverage to get the food and beverage trends of the target audience able to develop new ideas which can be used to inquire the target group about the concept to find a conclusion of the potential for commercialization or not with innovative food and beverage products to meet the need of target groups wanted then summarized in Product Design, there are 4 important sub-steps.

1) Factors of product selection (Criteria for Product Selection)

2) make a difference in the product (Differentiation)

3) Find several standard recipes and imitations to find the best starting one (Benchmark Formula)

4) Study the laws related to food and beverages from both raw materials and processes to ensure the safety of consumers (Food Raw)

Phase 2 Prototype

This section develops innovative food and beverage prototypes as they have been designed in 3 steps.

1) Using technology in food and beverages to develop new products according to Product Design. 
2) Take the product for a sensory test from a food and beverage expert.

3) Put the product to market test to assess characteristics and acceptance with the target audience

\section{Phase 3 Industry Scale and Commercialization}

This section is divided into 2 steps.

1) The formula was expanded in large quantities to produce a taste like acceptance test by making it in the form of a prototype, ready for requesting capital or investing in products

2) Develop an effective and practical business plan with able to strategize bringing products to the commercial market

The Post Launch section is a review of the potential of the after-sales product in order to make the entire operation process efficient and expand the results to be able to extend add a product line by going to the Product Design phase which is a small improvement made to the product to add or reduce something to suit the trend including the packaging, colors and details on the original bundle beginning to design a new product as Incremental Innovation. In the other hand, which is Breakthrough Innovation by developing a transformative product with a target audience and various details from the original database by looping to start at Concept Development and following the same sequence of steps. Therefore, developing innovative food and beverage products based on this prototype can be easily improved and developed.

The development of this new model by study a valuable process from theories and models that are efficient. In addition to getting a complete Stage Gate Process, that is suitable for entrepreneurs, it can also bring the advantages of Design Thinking to reach the real consumer needs to meet the unmet need of consumer. It also takes with the time to set as an indicator to complete the development of the innovative product according to the set goals or tailored to each company or organization. For example, phase 1 takes 1 week to get product design, phase 2 takes 2 weeks to get prototype and phase 3 takes 1 week to launch product in real target market and start preparing to develop production lines in the future.

4.2 Part 2 The developed model was tested for acceptance by SME entrepreneurs to find out the deficiencies. Difficulty to implement or not and more understand, also, it can be imagines from different steps and can be used for real purposes.

The study results estimate the acceptance of the food and beverage innovative product development model from the focus group has shown that the percentage of the results of the study from the Focus group, 2 rounds of 25 people each concluded that 50 participants in the focus group were all interested in starting to develop innovative products to achieve $100 \%$ competitiveness at present. Divided by occupation is 60\% of SME Entrepreneurs and the Researchers develop products (R\&D) that represent 15\% the same Food Stylize, Marketer, Nutritionist $15 \%$ more than food consultants $5 \%$ and chefs $5 \%$.

Most of the entrepreneurs develop food and beverage products according to their popularity in the market by listen to the market trend $75 \%$ while followed by their creativity is $60 \%$ In the meantime, $35 \%$ joint investments with those who already have products and $25 \%$ hire an expert to create a product, $20 \%$ do the research seeking the customer needs before product development and $10 \%$ buy franchise.

Learning about the food and beverage innovative product development models point out that almost $70 \%$ never develop products by following the theory of product development and $30 \%$ have done the theory following the product development. 
80 percentage of food and beverage entrepreneurs felt that it was easy to understand at a good level after understanding the Model and 15\% thought it was easy to understand at a very good level and 5\% thought it was at a moderate level.

It is $85 \%$ will use the Model as a roadmap for further product develop process approach and $15 \%$ will study more before applying in the future.

The entrepreneurs have studied step by step of the food and beverage innovative product development model, it makes easier to understand and have more direction for product development to bring about new products or processes in lower costs and increased income. There is a proper use of time and save resources, including raw materials, personnel, as well as reducing environmental destruction and using full efficiency resources. This model is role as a circle can be made more products line from the same resources which is back to create from the detail of the product design and also, can be start a new thing on the concept development.

Suggestion of discussion has shown that they believe that the model could be managed the step to work out and reduced the risk from new products before launching products to the market and also they want a platform that makes it easier and there is a group together to complement each other with raw materials and sales both internal and export markets.

\section{CONCLUSION}

Food and drinking water are important factors that the body needs. Food is intertwined with local cultures and wisdom of each country of the world which reflects the food that tells the uniqueness of different countries. To develop into a variety of food and beverages expresses the traditional culture, living and also uses raw materials such as local spices and herbs created food and drink. It is forwarding and communicating its uniqueness to different places to lead the food and beverage industry highly competitive. This research result aimed to study the process of developing innovative products that can be applied to food and beverage products and based on the acceptance of the food and beverage innovative product development model.

The methodology designed to develop innovative product processes for food and beverage model with a systematic review of the literature and to estimate the acceptance of the food and beverage innovative product development model using the focus group method.

The finding of the literature to consider various ideas and theories, found that discussed in a wide gap. The product life cycle cannot go on as the market changes, so there are limitations. Led to create of food and beverage innovative product development model which is divided into stages in the management of each part into 3 parts, Part 1 Product Design Development, Part 2 Prototype and Part 3 Industry Scale and Commercialization. Then find out the acceptance of the model known that many entrepreneurs of small business did not develop a systematic product, made it failed in a situation with a lot of competitors in the market and difficulty adapting and solving problems. When entrepreneurs have studied the model, it makes easier to understand and have more direction for product development.

Research limitations, It would be easy for entrepreneur in future might be added in about simple digital platform for the market and road map tool to sustainability outcome. Originality/value can be brought about new products or processes in lower costs and increased income. There is a proper use of time and save resources, including raw materials, personnel, as well as reducing environmental destruction and using full efficiency resources.

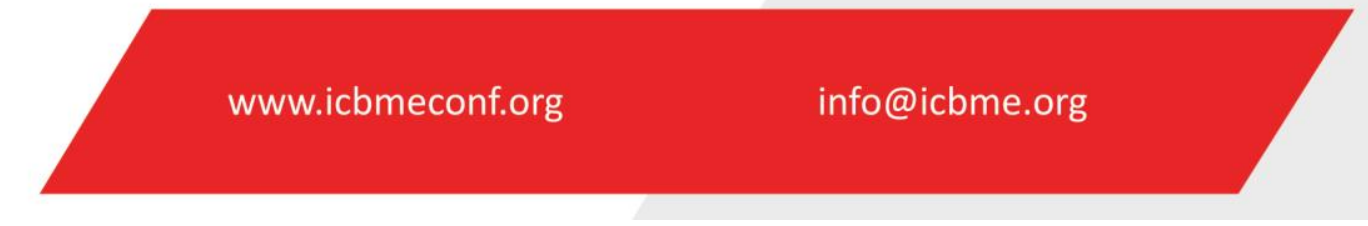




\section{$4^{\text {th }}$ International Conference on BUSINESS, MANAGEMENT \& ECONOMICS}

15 - 17 DECEMBER 2020

BERLIN, GERMANY

\section{ACKNOWLEDGEMENT}

I would like to thank all the Advisors for giving advice, training, teaching, guiding me to create initiatives for the benefit of society. Thank you for the CUTIP program of Chulalongkorn University which provides opportunities to study, research, find information, support and push for students to see the value of education and self-development.

\section{REFERENCES}

Cooper, R. G. (2008). Perspective: The Stage-Gate ${ }^{\circledR}$ Idea-to-Launch Process-Update, What's New, and NexGen Systems*. Journal of Product Innovation Management, 25(3), 213-232. doi:10.1111/j.1540-5885.2008.00296.x

Dziallas, M. (2020). How to evaluate innovative ideas and concepts at the front-end?: A front-end perspective of the automotive innovation process. Journal of Business Research, 110, 502-518. doi:https://doi.org/10.1016/j.jbusres.2018.05.008

InteractionDesignFoundation. (2010). Design Sprint. Retrieved from https://www.interactiondesign.org/literature/topics/design-sprint. design.org/literature/topics/design-sprint

https://www.interaction-

Knapp, J. (2016). Sprint: How to Solve Big Problems and Test New Ideas in Just Five Days.

Kocakulah, M. C., \& Austill, A. D. (2006). Product development and cost management using target costing: a discussion and case analysis. Journal of Business \& Economics Research (JBER), 4(2).

SMEThailand. (2019). why Thai SME cannot access research and innovation?

smethailandclub. (2016). SMEs must know : how to develop products attract the consumers. Retrieved from https://www.smethailandclub.com/news-6681-id.html

Terrar, D. (2018). Stanford d. School Design Thinking Process. Retrieved from http://www.theagileelephant.com/what-is-design-thinking/. http://www.theagileelephant.com/what-is-design-thinking/

Thanasopon, B., Papadopoulos, T., \& Vidgen, R. (2016). The role of openness in the fuzzy front-end of service innovation. Technovation, 47, 32-46. doi:https://doi.org/10.1016/j.technovation.2015.11.007

UKEssays. (2018). Product Life Cycle Theory. Retrieved from https://www.ukessays.com/essays/marketing/product-life-cycle-theory-marketingessay.php?vref $=1 . \quad$ Retrieved Accessed 20 October 2020 https://www.ukessays.com/essays/marketing/product-life-cycle-theory-marketingessay.php?vref=1 